\title{
An Enterprise-Wide Project Quality Management System in Manufacturing Industry
}

\author{
Wuliang Peng ${ }^{1,2}$, Rui $\mathrm{Lu}^{1}$ and Chengen Wang ${ }^{\mathrm{I}}$ \\ ${ }^{1}$ Key Laboratory for Process Industry Automation, Ministry of Education, Northeastern \\ University, Shenyang 110004, Liaoning, P.R. China \\ Peng-wuliang@163.com Luruihappy@163.com wangc@mail.neu.edu.cn \\ ${ }^{2}$ Computer Center, Shenyang Ligong University, Shenyang 110168, Liaoning, P.R. China \\ Peng-wuliang@163.com
}

\begin{abstract}
The new version of ISO 9000 approved in 2000 is studied and the relationships between operation processes and project processes are analyzed. According to the characteristics of manufacturing industry, the two-step tailoring method is presented to realize the project quality management from the ISO standards. The quality management models are built with the objectoriented method, including organization model, function model, process model and information model. The models harmonize the relationships between project processes and operation processes, and the enterprise-wide quality management system is achieved at three levels: the company, the project management office and projects. Finally, based on the presented models, the quality management information system is developed on the J2EE platform.
\end{abstract}

Keywords: Quality management, Project management, Business process management, Enterprise-wide applications, Enterprise model

\section{INTRODUCTION}

ISO 9000 standards have been adopted and implemented by more than 776,608 organizations in 161 Countries for their systematism and practicability [1]. Companies have been certified for ISO 9000 not only to improve the quality of products but also to enhance their images in their industry. However, ISO 9000 QS has not been quite as effective as expected since it was introduced in manufacturing industry. It is difficult to implement ISO 9000 in manufacturing industry due to various barriers, such as perceived misunderstanding of the ISO9000 concepts and methods of implementation, lack of a standard business process, heavy loads of paper work for management and extra documentations. In particular, more paperwork and more time spent on quality management were seen to be one of major negative outcomes of ISO 9000-certified quality systems [2].

Despite various problems encountered in the implementation of ISO 9000 , only a few researches and developments have been reported for project quality management information systems. The U.S. Corps of Engineers have utilized CAD and multimedia technology for quality assurance [3, 4]. ProjectPointk [5], Citadon CW [6], and ProjectTalk [7] are among the web-based collaboration systems that can give

Please use the following format when citing this chapter:

Peng, W., Lu, R., Wang, C., 2007, in IFIP International Federation for Information Processing, Volume 255, Research and Practical Issues of Enterprise Information Systems II Volume 2, eds. L. Xu, Tjoa A., Chaudhry S. (Boston: Springer), pp. 1335-1346. 
opportunities to improve communications between various project participants. Although they support information management focusing on the document sharing and exchanging over the Internet, the process-based QS information management has not been included. Sangyoon Chin et al. have presented a process-based quality management information framework to improve the productivity of the quality system (QS) process based on the new version of ISO 9000 approved in 2000[8].

In classical manufacturing industry, most of the work is executed as operation processes which are repeatedly executed. In order to achieve technical innovation and customizing products, modern manufacturing companies are increasingly using projects to organize and manage their work, and there is a growing need for the project quality management. The quality management of projects is more different from that of operation processes, while a project process are made up of many operation processes. Although many researches have been done on project quality management, due to focusing on project-oriented companies (e.g. construction industry) [8-10], the relationships between project quality management and operation process quality management have not been well studied up to now. In manufacturing industry, the researches on the quality management have not attached importance to projects so far [11-14].

In this paper, we have analyzed the processes in manufacturing industry in an enterprise-wide context and built the quality management models in which both project processes and operation processes are considered. The models include an organization model, a functional model, a process model and an information model. Based on those models, a quality management information system is developed on the J2EE platform.

\section{ENTERPRISE QUALITY MANAGEMENT AND PROJECT QUALITY MANAGEMENT}

The ISO 9000:2000 standards emphasize the process approach of QS, which means that all processes, their management, and their mutual interactions are inter-related. The process approach enables interlinks of processes within QS, where each process runs based on "Plan-Do-Check-Act" (PDCA) [10]. In order to build the enterprise quality management system by using the process approach, all the processes in the company must be defined and managed. The processes in modern manufacturing companies can be classified into project processes and operation processes according to the repeatability and stability of the process, while the project processes have oneoff character and operation process should be repeatedly executed. Therefore, the enterprise quality management system based on ISO9000:2000 in manufacturing companies should manage the quality of both project processes and operation processes, all of which are run as PDCA cycles. Taking the management responsibility and resource management into account, the enterprise quality management system can be addressed through a three-dimensional model as shown in figure 1 . There are organization units taking on respective management responsibilities of enterprise quality management on the organization dimension. All the processes in a company to be executed based on PDCA cycle as shown in the time 
dimension. As objects to be managed, two types of processes, i.e., project and operation processes are listed on the object dimension.

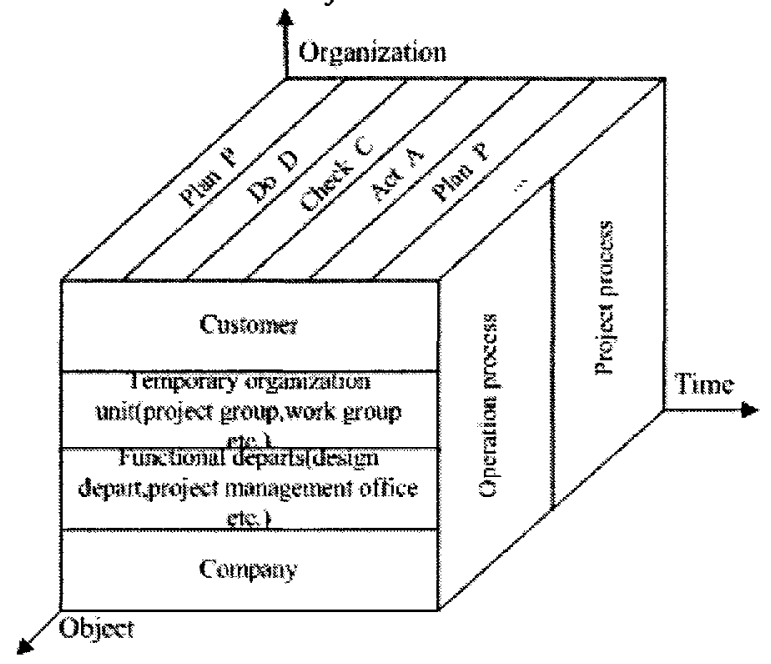

Figure 1. QS Model in Modern Manufacturing Industry

\section{IMPLEMENT OF QUALITY MANAGEMENT SYSTEM IN MODERN MANUFACTURING INDUSTRY}

As aforementioned, the quality management of project processes is an important component of QS in modern manufacturing industry. The quality management of projects has its particular characteristics other than that of operation processes while there are close relationships between project processes and operation processes. The implement of quality management system in modern manufacturing industry should support the quality management of both operation processes and project processes.

\subsection{Characteristics of the Project Quality Management in Manufacturing Industry}

The characteristics of project quality management depend on the characteristics of projects. The project quality management in manufacturing industry has its particular complexities in contrast with that in other industries for the following reasons: (1)High uncertainty: As a knowledge-intensive and creative process, every project in manufacturing industry is hard to learn from previous experiences, and therefore, the factors that influence the project quality make up of a grey system, (2)Nonstandard definition of project process: Because each project has its particular features, and is not repeatable, therefore it is impossible to define a standard project process for all the 
projects in a company, (3) Difficulty for quality assurance. The project quality is scattered in a large numbers of semi-finished products, which are not only in the form of physical entities, but also in the form of electronic documents, (4) Particular quality control method: For its knowledge-intensive character, the project quality controls are often executed by experts in the professional field, and (5) Complex relationships between project processes and operation processes: The quality management in manufacturing industry must control the quality of both projects and operation processes.

\subsection{Implementing of the Quality Management System in Manufacturing Industry}

For adapting to the various characteristics of quality management in various industries, ISO9000:2000 enhances the flexibility and tailoring possibilities [10]. In a sense, it can be said that the implementation of ISO 9000 is a tailoring process for the quality management of a special company based on ISO9000:2000 standards. ISO9000:2000 is process-oriented, and the QS based on ISO9000:2000 should focus on defining and managing the processes used in a company. However, project processes can hardly be defined as standard processes because it is not repeatable. In this paper, we present a two-step tailoring method to realize the quality management for projects, as shown in fig. 2. With this method, the first step is to tailor for a special company based on ISO9000:2000 standards, and the result is that the process models of all the operation processes and the reference process models for all kinds of project in the company are defined based on ISO9000:2000 standards. The second step is to tailor for a special project, and the result is that the process of a special project is defined from an appropriate reference process model defined in the first step. Through those two steps, the definability and manageability can be achieved for the project quality management in manufacturing industry.

The macro-process of a special project can be inspected through the inspection activities inside in the defined project process tailored from a reference process model. At the same time, the project contains a large numbers of operation processes such as design processes, manufacture processes etc. All those operation processes must be run according to the operation process models defined in the enterprise QS. Therefore, the quality management of project in manufacturing is composed of two components: the quality management of project process and the quality management of operation processes.

\section{MODELING THE QUALITY MANAGEMENT SYSTEM}

One reason for the widespread appeal of object oriented modeling is the natural mapping paradigm. This is made possible by the object construct, which allows a oneto-one mapping between objects in the system being modeled (e.g. project, quality document, process, etc.) and their abstractions in the object model $[15,16]$. Object oriented modeling also has a major effect on implementation through its facilitation of 
modular design and software reusability. Thus object oriented modeling applied to enterprise modeling and analysis can be potentially very beneficial. Project quality management requires enterprise-wide modeling approach at various levels of detail. In this paper, object oriented modeling is employed to analysis and design the organization model, function model and information model of project quality management system.

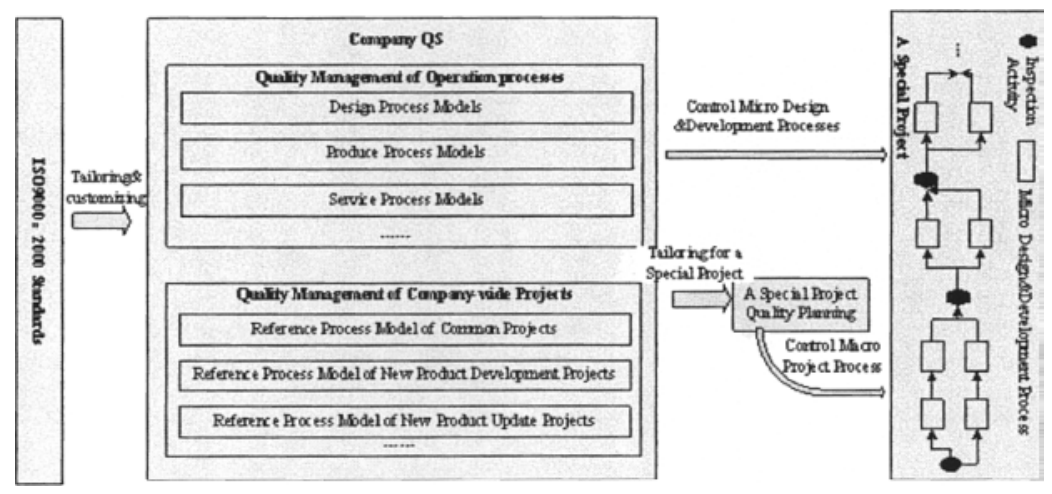

Figure 2. From ISO Standards to the Quality Management of Projects

\subsection{Organization Model}

Building an organization model helps to explicitly represent the structural relationships among various organizational subdivisions and employees who will use the information system. From the viewpoint of object orientation, an organization model is defined in actors that identifies the potential users and specifies what and how they expect the information systems to work.

In today's manufacturing company, a large number of projects are run, and then the traditional organizational structure divided by function should be replaced by the matrix organizational structure, in which two types of organization unit exist: the first is functional organization units based on a special group of functions, the second is project teams which are set up to create a unique product or service. In matrix organizational structure, the project managers are managed by project management office (PMO).

For enhancing the effectiveness of quality management, the functional organization unit called quality management office (QMO) should be set up to implement the company QS. Other organization units in functional organizational structure should work following the standard process models approved by QMO. For example, the design departments should perform design tasks following the standard design procedures defined in design process models. PMO has the responsibility to constitute the project procedures and monitor all the projects in a company. As a temporary organization unit, a project team must be set up for each project. Project team's top manager, called project leader, is supervised by PMO. Since the members of project 
team come from different functional organization units, the members of a project team have two bosses: the boss of the functional organization unit that they work in and the project leader of the project that they are working on at the moment. In conclusion, the main organization units that directly relate to the project quality management include QMO, PMO and project team, while the functional organization units are indirectly related because the members of project teams come from it.

\subsection{Function Model}

In UML (Unified Modeling Language), the use-case diagram is used to identify and describe requirements. There are two kind of use-case diagram: one is the business use-case diagram which is used to describe enterprise business, the other is the system use-case diagram which is used to define the function of an application system. This paper employs the system use-case diagram to draw up the function of the project quality management information system in manufacturing industry.

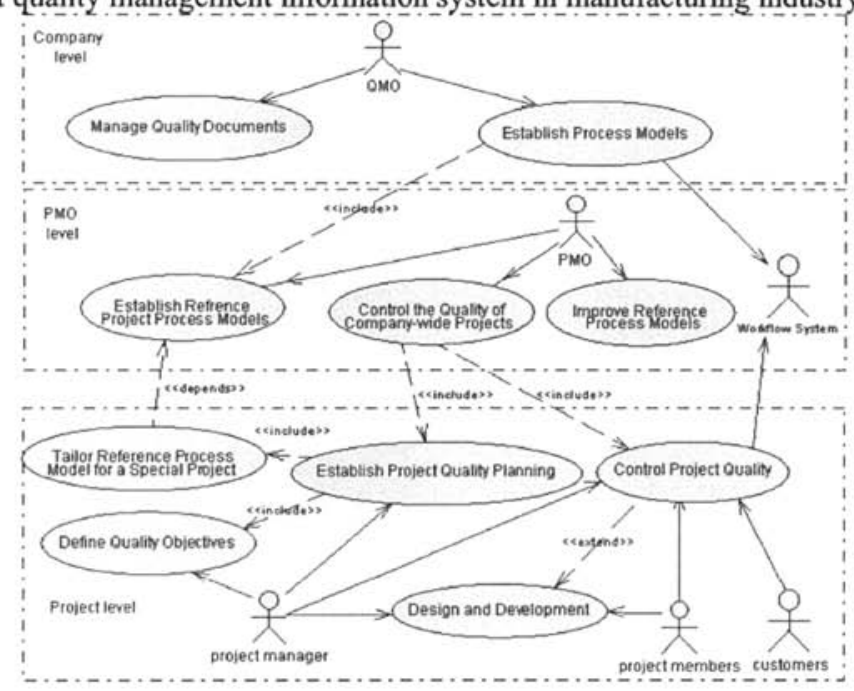

Figure 3. Function Model of QM

As described in the organization model, the actors of use-case diagram of project quality management can be defined as QMO, PMO, project leader and project members. As shown in figure 3, the quality management of project in manufacturing industry can be divided into three levels: QMO level, PMO level and project management level. QMO level is enterprise-wide quality management system, which implements and controls the quality of all the processes in a company. As an integral part of enterprise-wide quality management, PMO level is project-oriented quality management, which manages the quality of all the projects in a company. Cooperating with QMO, PMO defines the project procedures called reference project process models. Project leader is in charge of making up the quality plan for a special project based on the given reference project process model. PMO examines and 
approves the quality plans made up by project leaders, and inspects the project quality in term of the approved project quality plan.

\subsection{Business Process Model}

A project can generally be divided into four phases: start, plan, run and control, finish phase. Each phase consists of some sub-processes, which are operation processes mostly. Therefore, the quality management of projects must manage the quality both of the macro project process and of the micro operation processes.

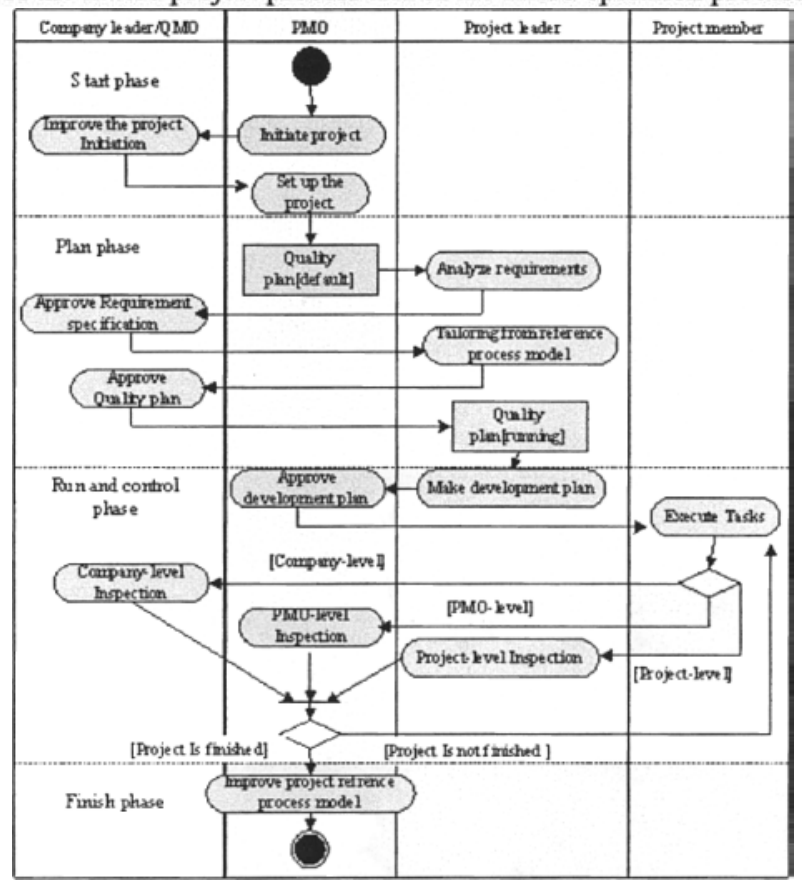

Figure 4. Process Model of QM

The business process model of the project quality management is described by the activity diagram as shown in figure 4 . During the start phase of project life-cycle, all the processes such as the initiation of a project, the study of project's feasibility etc. are managed by company top manager at QMO level. During the plan phase, project leaders make up all kinds of project plans, including quality management plan, schedule plan and risk management plan etc. All those plans are approved by PMO. During the run and control phase, the quality management should be executed at three levels: project level at which project manager manages the quality of special project, PMO level at which PMO examines the management processes of all the projects of company, company level at which the company top manager settles the serious problems of project and approves the import progress of projects. During the finish 
phase, the PMO analyzes the performance of the project process model and revises it to achieve the continuous improvement of enterprise project quality management.

\subsection{Information Model}

Through the presented organization model, function model and the process model, various types of information and their mutual relationships are identified and modeled by using the UML class diagram as shown in figure 5 . Since the information model consists of many classes and relationships, they need to be grouped into packages for ease of use, maintainability, and reusability. In this paper, four packages are presented, and they are (1) enterprise organization, (2) document, (3) enterprise project quality management, and (4) project. More details of each package are discussed below.

The enterprise organization package, in which the organization unit and responding management responsibility are defined, is abstracted from organization model. The company class represents a company and the organization unit class represents a functional organization unit undertaking a scope of work in a company. An organization unit has responding the management responsibility that is how an organization unit participates in QS. An organization unit contains some employees represented by the employee class.

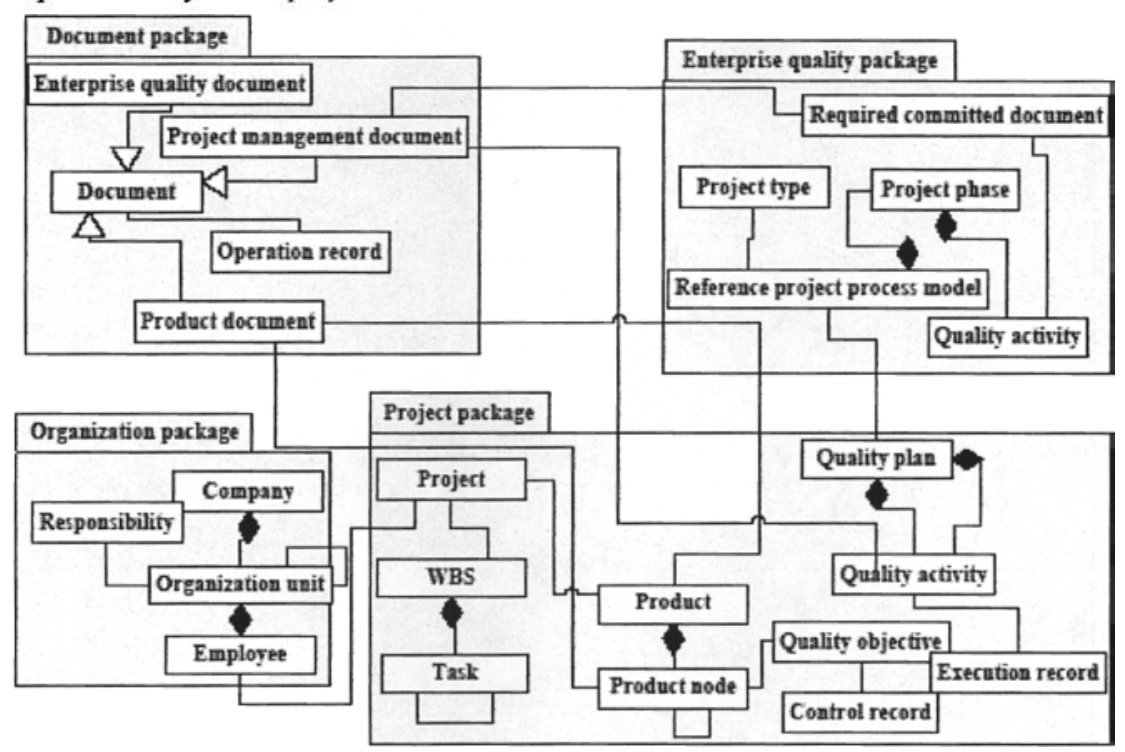

Figure 5. Information Model of QM

In the document package, there are some classes abstracting all kinds of documents, include enterprise quality document, project management document, product technology document etc. the enterprise quality document class represents the specification document of QS, e.g., the enterprise quality objective document, 
enterprise quality management policy document, process model specification document etc. the project management document class represents the management documents used in projects, such as project requirement document, project cahiers and summarization reports etc. The product document class represents the technodocuments such as CAD Documents.

The enterprise project quality package is used to represent the reference project process model. Each reference project process model instance is defined for one or more types of project. The project process model requires a project to be divided into some phases, which is abstracted as project phase class. The quality activity represented by the quality activity class is the activity that inspects the special project. When the quality activity is executed, some management documents that are defined by the required committed document class must be committed to examine and record the execution of a quality activity.

The project package contains all the classes that relate to the quality management of a special project. Since the quality plan of a project is tailored from reference project process model, the quality plan class is associated to the reference process model class. The quality plan is made up of some quality activities, and each quality activity has its execution records represented by the execution record class. Since the objective of a project is to design or develop a new product or service, the information of the product must be managed in the information model. The product is represented by the product class, while the semi-finished products are represented by the product node class. Each product node has its quality objectives represented by the quality objective class.

\section{ENTERPRISE-WIDE PROJECT QUALITY MANAGEMENT INFORMATION SYSTEM}

Based on the foregoing models, an information system, called the enterprise-wide project quality management information system (QMIS), is developed on the J2EE platform. The system can be divided into three sub-systems: enterprise quality management, enterprise project quality management and project quality management. 


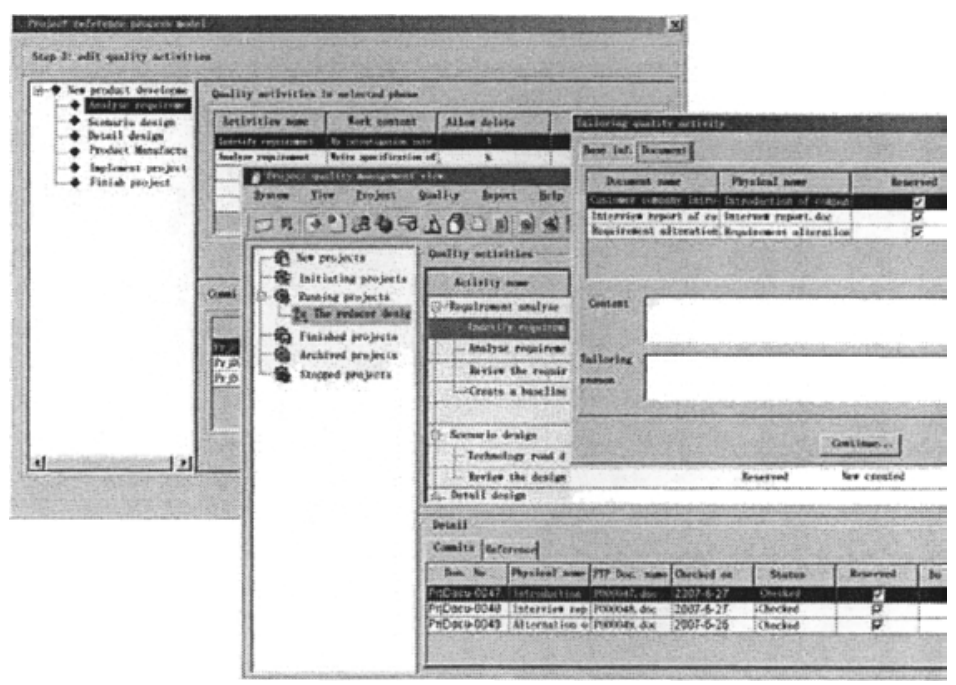

Figure 6. Representative Interfaces of QMIS

The enterprise quality management sub-system helps QMO to manage the enterprise-wide quality documents and the process models of operation processes. The enterprise project quality management sub-system is used by PMO to define reference project process models and control the quality of projects in the company. The project quality management sub-system aids project leaders to make up the quality plan of a special project and manage the project quality. Three-tier software architecture, including user interfaces, business logics and databases, is applied in this information system. The three-tier design enables more efficient system development by modularizing tiers and separating the application from the database, since this makes it easier to modify one tier without affecting the other tiers. Based on the class diagrams shown in Figs. 5, the databases, which are the tier 1, are developed by using MS SQL Server 2000. All files used in QS are managed through FTP service implemented by using Microsoft IIS Service. The tier 2 is business logics, in which the EJB technologies are employed by using Weblogic 8.1. The session beans in the EJB container are realized based on the use cases defined in the function model, while the entity beans are realized according to the databases schema defined in the tier 1 . The tier 3 is user-interfaces that are designed by using java swing. In addition, an open source work flow system, Shark2.0, is integrated to execute some processes automatically. The representative interfaces related to the quality management of project process are shown in figure 6.

\section{CONCLUSIONS}

The ISO 9000:2000 standards emphasize the process approach of QS. In modern company, two types of processes concurrently exist: the first is operation process that 
should be executed repeatedly, the second is project. Considering the complexities of the quality management in manufacturing modern company in which abound of projects are running, the two-step tailoring method is presented. QMO, PMO and project leaders cooperatively participate in the project quality management, and then both the macro project processes and the micro operation processes can be synthetically managed.

Through object-oriented method to build the models of the project quality management, the relationships among project quality management, enterprise quality management and enterprise management can be located. Therefore, the models and the application system given in this paper are enterprise-wide.

Implementing the quality management system project from the viewpoint of process, the project quality management can be continually improved. Employing information technologies to support the project quality management, the effectiveness and efficiency can be remarkably enhanced.

\section{REFERENCES}

1. ISO, The ISO Survey of ISO 9000 and ISO I4000 Certificates Eleventh Cycle: up to and including (2005). http://www.iso.org (Accessed December 31, 2005).

2. S.M. Dissanayaka, M.M. Kumaraswamy, K. Karim, and M. Marosszeky, Evaluating outcomes from ISO9000-certified quality systems of Hong Kong constructors, Total Quality Management. Volume 12, Number 1, pp.29-40, (2001).

3. D. Chu, A.L. Stumpf, L.Y. Liu, and S. Chin, Construction quality assurance in Corps of Engineers projects utilizing CADD systems, in Proc. of the 4th Construction Congress, (ACSE: New York, 1995), pp.503-510.

4. L.Y. Liu, A.L. Stumpf, and S. Chin, Global project documentation and communications using HTML on the World Wide Web, in Proc. of the 3rd Congress for Computing in Civil Engineering (ACSE: California, 1996), pp.15-20.

5. Autodesk, Homepage for ProjectPoint (Aug. 72005 ). http://www.buzzsaw.com.

6. Citadon, Homepage for Citadon (Aug. 7 2005). http://www.citadon.com.

7. MH2, Homepage for MH2 Technologies (Aug. 7, 2005). http://www.mh2.com.

8. S. Chin, K. Kim, and Y.-S. Kim, A process-based quality management information system, Automation in Construction. Volume 13, Number 2, pp.241-259, (2004).

9. I. hyvari, Project management effectiveness in project-oriented business organizations, International Journal of Project Management. Volume 24, Number 3, pp.216-225(2006).

10. C. Cianfrani, J. Tsiakals, and J. West, ISO 9001:2000 Explained, 2nd ed(American Society for Quality (ASQ), Milwaukee, WI, 2001).

11. R. Sousa, Linking quality management to manufacturing strategy: an empirical investigation of customer focus practices, Journal of Operations Management. Volume 21, Number 1, pp.1-18(2003).

12. R. McAdam and D. Leonard, An evaluative framework for TQM dynamics in organizations, International Journal of Operations and Production Management. Volume 23, Number 6, pp.52-77(2003).

13. D.I. Prajogo and A.S. Sohal, The integration of TQM and technology/R\&D management in determining quality and innovation performance, Omega. Volume 34, Number 3 , pp.296-312(2006).

14. Jun Deng, Zhong-hua $Y u$, Ji-ping Yang,et al., Product lifecycle total quality management system, Journal of Zhejiang University(Engineering Science). Volume 39, Number 4, pp.500-504(2005). 
15. G. Booch, J. Rumbaugh, I. Jacobson, The Unified Modeling Language User Guide, Addison Wesley Longman, Inc, 1999.

16. S. Biswas, Y. Narahari, Object oriented modeling and decision support for supply chains, European Journal of Operational Research. Volume 153, Number 3, pp.704-726(2004). 